\title{
THE EFFECT OF DIFFERENT DENTAL ADHESIVE SYSTEMS ON HYBRID LAYER QUALITIES
}

Ku SH, Tan YS, Yahya NA. The Effect of Different Dental Adhesive Systems on Hybrid Layer Qualities. Annal Dent Univ Malaya 2014; 21(1)

\begin{abstract}
The study aimed to evaluate the quality of the hybrid layer form by three different adhesive systems. Class V cavities were prepared on the buccal surface of fourty extracted human premolars. The prepared teeth were randomly assigned into four groups according to the adhesive system and application mode. The systems were: Optibond S (OS, total-etch); Optibond Versa (OV, two-bottles, self-etch); Single Bond Universal (SBU, one-bottle, self-etch) and Single Bond Universal with etchant (SBU + etchant). All cavities were restored with composite (Filtek Z350XT). The samples were sectioned, polished and pretreated to remove minerals, protein and water prior to SEM evaluation. From the images, thickness of the hybrid layers was measured. Present of resin tags and adaptation failure were also recorded. The data obtained were analyzed using ANOVA, Dunnett's T3, Kruskal-Wallis and Mann-Whitney tests. OS group showed the highest average hybrid layer thickness (4.34 $\mu \mathrm{m})$, followed by SBU + etchant $(3.06 \mu \mathrm{m}), \mathrm{OV}(1.91 \mu \mathrm{m})$ and SBU $(0.95 \mu \mathrm{m})$. Both adhesive and cohesive failures were observed in SBU group. Present of prominent resin tags were seen in both OS and OV groups. In conclusion, all the investigated adhesive systems were able to perform distinguishable actions as shown in micro-morphological alteration and hybrid layer thickness. Two-bottles, selfetch adhesive (OV) was proven to produce negligible adaptation failure compared to other adhesive systems in the present study. Combined all-in-one adhesive (SBU) was found to render a superior bonding performance in total-etch mode comparing to self-etch mode.
\end{abstract}

Keywords: Total-etch, self-etch, hybrid layer, resin tags, adhesive failure, cohesive failure

\section{INTRODUCTION}

In the past four decades, adhesive dentistry has revolutionized restorative dental practice with the progressive improvement in adhesive materials. Reliable and long lasting resin-based composite fillings are currently available for aesthetic tooth colored restorations. Evolution of the first generation of adhesive system to the current adhesive materials was inevitably aiming at simplification of clinical procedures such s reduction of the application time and steps.

Original Article

\author{
Ku $S H^{1}$, Tan $Y S^{1}$, Yahya $N A^{2}$ \\ ${ }^{1}$ Faculty of Dentistry, University of Malaya, Kuala \\ Lumpur, Malaysia. \\ ${ }^{2}$ Biomaterial Technology Research Group and \\ Department of Restorative Dentistry, Faculty of \\ Dentistry, University of Malaya, Kuala Lumpur, \\ Malaysia.
}

\section{Corresponding Author: \\ Dr Noor Azlin Yahya \\ Email:nazlin@um.edu.my}

It has been widely accepted that acid conditioning of the enamel as pretreatment prior to the application of the composite resin (1). The acid etchant completely removed the smear layer and smear plugs which then allows capillary penetration of adhesives into the etched enamel surfaces to form resin tags. The resin tags provide micromechanical interlocking bond between enamel and resin (2). However, bonding of resin to dentine was proven to be more complicated than bonding to enamel (3). This is due to the complex morphology and chemical composition of the dentine, specifically with respect to its moisture and high organic content. After selective demineralization of the dentine, application of a suitable intermediate layer which is dentine adhesive seems to be a solution. The adhesive should penetrates the exposed collagen fibre network and infiltrate into the dentinal tubules $(4,5)$. The interface between the dentine and adhesive is called 'hybrid layer'. This layer was first described by Nakabayashi (6) in order to explain the phenomenon of dentine bonding.

Over the years, durability and reliability of adhesives restoration have been promoted by the advancement of adhesive systems (7). From the Buonocore era to present, there are several factors that characterize the change in adhesive systems: enamel etching, dentine etching, modification of the smear layer, and handling properties. Adhesive systems are usually categorized by generation based on when they were introduced, with the newer generation claiming to be superior over the earlier generation (e.g., self-etch and total-etch). There is also another classification that uses the number of bottles or steps rather than the generation. This type of classification is based on total-etch and self-etch mode of applications (8). 
Total-etch adhesive systems is known to produce efficient and stable bonding to enamel and dentine through production of higher resin-dentine bonds that are more durable than most one- and two-step self-etch adhesives $(8,9)$. Initially, only the enamel surfaces were etched. Later, the etchant was extended to dentine surface. When hydrophilic monomers were introduced, a reliable bond to dentine was achieved of which enabled resin penetration of dentine due to wetting of the dentine $(10,11)$. This system is marketed as either two-bottle or three-bottle system. Bonding agent and primer are combined in the two-bottle system, whereas in the three-bottle system, a primer needs to be applied prior to bonding agent. Despite being commonly referred to as three-bottle or two-bottle system, etchants are usually delivered in a syringe rather than in a bottle. Phosphoric acid with varying concentration $(10 \%$ to $40 \%$ ) was often used as the main component in the etchant. Precaution must be taken not to over etch and over expose the dentine to the etchant (12) as it may cause the collagen fibre network to collapse hence preventing successful infiltration of the adhesive material.

Self-etch adhesive system reduces the number of steps needed for bonding to enamel and dentine. They consist of either a two-step system that comprise the use of a primer with added etchant followed by the bonding agent (two separate bottles), or a single step system that integrates all steps into one. This single step system use either a solution in one bottle or two separate bottles that require premixing prior to application.

Previous studies showed a superior result of bonding with total-etch compared to self-etch adhesive systems $(13,14,15)$. However, both the total-etch and self-etch adhesive systems are effective for dentine bonding despite of the formation of thinner hybrid layer by the later system $(16,17,18)$.

A good adaptation between tooth surface and the restorative material is very important for the survival of a restoration. Previously, two main types of adaptation failures have been observed (19). Firstly, is the adhesive failures which occur either between the adhesive and dentine or adhesive and composite restoration. The second type of failure is known as cohesive where there is internal breakdown of the adhesive itself (20). The combination of adhesion and cohesion will determine the overall bonding strength in every restoration involving an adhesive and a substrate.

Currently, there are many new adhesive systems available in the market with each product claimed by their manufacturers to perform better compare to the others. However, there is lack of studies that evaluate the bonding efficiency for these latest adhesive systems. One of the first and most widely accepted tools to evaluate the quality of the hybrid layer and the present of adaptation failures is the scanning electron microscope or SEM (21). Therefore, the objectives of the present study were to evaluate the thickness of the hybrid layer, present of the resin tags, present of adhesive and/or cohesive failures in dentineadhesive bonded interfaces of the three latest adhesive systems (Optibond S, Optibond Versa and Single Bond Universal) using SEM. The null hypothesis was that there are no differences in the micro-morphological appearance of the dentine-adhesive bonded interfaces of the three evaluated adhesive systems.

\section{MATERIALS AND METHODS}

Approximately fifty freshly extracted sound human premolars were collected from several clinics in Malaysia. However, only teeth which were free from decay, cracks or restorations were selected for this study. Soft and hard tissue deposits were cleaned with pumice and removed using ultrasonic scaler. The teeth were then disinfected using $0.5 \%$ Chloramine $\mathrm{T}$ for a week, stored in distilled water and placed in an incubator at $37^{\circ} \mathrm{C}$ before use.

Class V cavities were prepared using straight diamond burs in a high-speed water-cooled handpiece at $1 \mathrm{~mm}$ above the cementoenamel junction on the buccal surface of the premolars. Dimensions of each preparation were $4 \mathrm{~mm}$ mesiodistally, $2 \mathrm{~mm}$ occlusogingivally, 1.5 $\mathrm{mm}$ depth and $90^{\circ}$ cavosurface angles. A bevel was made on the enamel part of each cavity using a flame-shaped bur. The teeth were then randomly divided into four groups of ten specimens each. The materials used in this study and their compositions are presented in Table 1.

The prepared teeth of each group were restored following the manufacturers' instruction. Prior to placement of the composite: In Group 1 (OS), the cavities were etched with etchant for $15 \mathrm{~s}$ on the enamel and $10 \mathrm{~s}$ on the dentine. The cavities were then rinsed thoroughly and gently air dried. This was followed by application of bonding agent for $15 \mathrm{~s}$, air thinned for $3 \mathrm{~s}$ and then light cured for $20 \mathrm{~s}$. In Group $2(\mathrm{OV})$, the cavities were treated with a two-bottle system, self-etching bonding agent where primer was applied for $20 \mathrm{~s}$ using scrubbing motion and air thinned for $5 \mathrm{~s}$. Next, adhesive was applied for $15 \mathrm{~s}$, air thinned for $5 \mathrm{~s}$ and then light cured for $10 \mathrm{~s}$. In Group 3 (SBU), the cavities were treated with a single bottle in self-etching mode. The cavities were scrubbed with adhesive using a microbrush for $20 \mathrm{~s}$, air dried for $5 \mathrm{~s}$ and then light cured for $10 \mathrm{~s}$. In Group 4 (SBU + etchant), the cavities were treated with SBU in total-etching mode where the etchant was applied on both enamel and dentine surfaces. This was followed by the same procedures as in Group 3.

All class $\mathrm{V}$ cavities were then restored with composite using incremental technique and each layer was light cured for $40 \mathrm{~s}$. The restored teeth were mounted vertically using clear cold curing epoxy resin (Mirapox 950-230 A) in plastic holder according to the four different groups. Subsequently, the teeth were sectioned 
Table 1: Chemical formulations of adhesive systems, etchant and resin composite used in this study.

\begin{tabular}{|c|c|c|c|}
\hline Material (Manufacturer) & Code & Type & Composition \\
\hline OptiBond S, (Kerr, CA, USA) & OS & $\begin{array}{l}\text { Primer-adhesive } \\
\text { (Total-etch) }\end{array}$ & $\begin{array}{l}\text { Ethyl alcohol } 20-25 \% \text {, Alkyl dimethacrylate resins } 55-60 \% \text {, Barium } \\
\text { aluminoborosilicate glass } 5-10 \% \text {,Fumed silica } 5-10 \% \text {, Sodium } \\
\text { hexafluorosilicate } 0.5-1 \% \text {. }\end{array}$ \\
\hline $\begin{array}{l}\text { Optibond Versa Primer (Kerr, } \\
\text { CA, USA) }\end{array}$ & $\mathrm{OV}$ & Primer & $\begin{array}{l}\text { Acetone } 25-35 \% \text {, Ethyl alcohol } 4-15 \% \text {, Hydroxyethylmethacrylate } \\
\text { (HEMA) } 30-50 \%\end{array}$ \\
\hline $\begin{array}{l}\text { Optibond Versa Adhesive } \\
\text { (Kerr, CA, USA) }\end{array}$ & & $\begin{array}{l}\text { Adhesive } \\
\text { (Self-etch, two- } \\
\text { bottle) }\end{array}$ & $\begin{array}{l}\text { Ethyl alcohol } 20-30 \% \text {, Alkyl dimethacrylate resins } 47-68 \% \text {, Barium } \\
\text { aluminoborosilicate glass } 5-15 \% \text {,Fumed silica } 3-10 \% \text {, Sodium } \\
\text { hexafluorosilicate } 0.5-3 \%\end{array}$ \\
\hline $\begin{array}{l}\text { Single Bond Universal (3M } \\
\text { ESPE, St Paul, MN, USA) }\end{array}$ & SBU & $\begin{array}{l}\text { Primer-adhesive } \\
\text { (Combined Total- } \\
\text { etch, Self-etch and } \\
\text { Selective-etch, single } \\
\text { bottle) }\end{array}$ & $\begin{array}{l}\text { Methacryloxydecyl phosphate monomer, Dimethylcrylate resins, } \\
\text { HEMA, Vitrebond }{ }^{\mathrm{TM}} \text { Copolymer, Filler, Ethanol, Water, Initiator, } \\
\text { Silane }\end{array}$ \\
\hline Gel Etchant (Kerr, CA, USA) & - & Etching agent & Phosphoric acid 37.5\%, Water, Fumed silica, Dye colorant \\
\hline $\begin{array}{l}\text { Filtek }^{\mathrm{TM}} \text { Z350XT ( } 3 \mathrm{M} \text { ESPE, } \\
\text { St Paul, MN, USA) }\end{array}$ & - & $\begin{array}{l}\text { Light-cured, } \\
\text { universal, nano- } \\
\text { hybrid composite }\end{array}$ & Bis-GMA, UDMA, TEGDMA,Bis-EMA(6) resins \\
\hline
\end{tabular}

bucco-lingually through the restoration with a low-speed precision cutter (Micracut 125). Each tooth was sliced as such to produce one specimen, approximately $3 \mathrm{~mm}$ in width, with a flat surface on both sides. Ten specimens for each group were prepared resulting in a total number of fourty specimens. The specimens were then polished for few minutes with an increased grit of silicon carbide paper (600 grit, 800 grit, 1000 grit) under running water (22). Next, the specimens were immersed in distilled water and placed in the ultrasonic bath to remove the smear layers and debris.

The specimens were then demineralized using $6 \mathrm{~N}$ $\mathrm{HCl}$ for $1 \mathrm{~min}$, rinsed in distilled water, deproteinized with $12 \% \mathrm{NaOCl}$ for $10 \mathrm{mins}$, followed by another rinsing with distilled water. The specimens were then cleaned with ultrasonic cleaner to completely remove the chemicals. Next, the samples were dehydrated in ascending concentration of ethanol (25\% for $20 \mathrm{mins}, 50 \%$ for 20 mins, $75 \%$ for $20 \mathrm{mins}, 95 \%$ for $30 \mathrm{mins}, 99 \%$ for 60 mins) (23). After dehydration, the samples were kept in a petri dish at room temperature for $24 \mathrm{hrs}$. The evaluation of the resin-dentine interface of the specimens was conducted using low vacuum SEM (Quanta-FEG 50, FEI, Germany). A minimum of three SEM images were taken for each sample. The working distance and magnification were standardized for each image.

\section{EVALUATION CRITERIA}

The general aspect of resin-dentine interface after the application of adhesive and hybridization was examined, with particular attention being paid to:
- Thickness of the hybrid layer

- Resin tags (presence or absence);

- Adaption failure (adhesive or cohesive failure).

\section{STATISTICAL ANALYSIS}

The data obtained were analyzed using Statistical package for the social science (SPSS) software version 12.0.1 for Windows. Descriptive data were expressed as mean $[ \pm$ standard deviation (SD)]. Numeric values were compared with t-test and One-way ANOVA or non -parametric Mann-Whitney $U$ and Kruskal-Wallis tests, where appropriate. Post-hoc test was performed for further multiple comparison and the results were reported with a Benferroni method adjustment.

\section{RESULTS}

The mean average thickness of the hybrid layers are displayed in Table 2. Statistical analysis was performed using one-way ANOVA and Dunnett's multiple comparison at a $95 \%$ confident interval. The hybrid layer thickness for all groups were significantly different $(\mathrm{p}=$ 0.000 ). The mean average hybrid layer thickness were significantly different $(\mathrm{p}<0.05)$ between Group OS and OV $(p=0.002) ;$ OS and SBU $(p=0.000)$; OV and SBU (p $=0.022)$; SBU and SBU + etchant $(\mathrm{p}=0.004)$.

The median percentages of the adaptation failure for all groups are shown in Table 3. Statistical analysis was carried out using Kruskal Wallis test. Statistical result showed significant differences among all the groups for 
all types of adaptation failures. There were no significant differences detected between all the groups in the cohesive failure. Multiple group comparison was done using MannWhitney's with Bonferroni correction $(p<0.0083)$. From the multiple comparison test, two pairs of groups differed significantly (OS and SBU, p $=0.004$; Group OV and SBU, $p=0.001)$ in composite-adhesive adaptation failure. Whereas, OV and SBU were significantly different $(\mathrm{p}=$ 0.006) in dentine-adhesive adaptation failure.

Table 2: The mean average hybrid layer thickness.

\begin{tabular}{lll}
\hline $\begin{array}{l}\text { Types of Adhesive } \\
\text { Systems }\end{array}$ & $\begin{array}{l}\text { Mean average thickness } \\
\text { of hybrid layer }(\mu \mathrm{m})(\mathrm{SD})\end{array}$ & $P$ Value \\
\hline OS $(\mathrm{n}=10)$ & $4.34(1.46)$ & \\
OV $(\mathrm{n}=10)$ & $1.91(0.75)$ & $\leq 0.000^{*}$ \\
SBU $(\mathrm{n}=9)$ & $0.95(0.45)$ & \\
SBU + etchant & $3.06(1.34)$ & \\
$(\mathrm{n}=10)$ & & \\
\hline
\end{tabular}

Values are means (standard deviations) in $\mu \mathrm{m}$.

* Significant if $\mathrm{p}<0.05$

Table 3: The percentages of the adaptation failures.

\begin{tabular}{|c|c|c|c|c|c|}
\hline $\begin{array}{l}\text { Types of } \\
\text { Adaptation } \\
\text { Failures }\end{array}$ & $\begin{array}{c}\text { OS } \\
\text { Median } \\
\text { (IQR) }\end{array}$ & $\begin{array}{c}\text { OV } \\
\text { Median } \\
\text { (IQR) }\end{array}$ & $\begin{array}{c}\text { SBU } \\
\text { Median } \\
\text { (IQR) }\end{array}$ & $\begin{array}{l}\text { SBU + } \\
\text { etchant } \\
\text { Median } \\
\text { (IQR) }\end{array}$ & $P$ Value \\
\hline $\begin{array}{l}\text { Adhesive } \\
\text { failure } \\
\text { (composite- } \\
\text { adhesive) }\end{array}$ & $\begin{array}{c}3.33 \\
(8.44)\end{array}$ & $\begin{array}{c}0.00 \\
(6.88)\end{array}$ & $\begin{array}{c}17.08 \\
(54.17)\end{array}$ & $\begin{array}{c}12.76 \\
\text { (3) }\end{array}$ & $0.005^{*}$ \\
\hline $\begin{array}{l}\text { Cohesive } \\
\text { failure } \\
\text { (within } \\
\text { adhesive } \\
\text { layer) }\end{array}$ & - & $\begin{array}{c}0.00 \\
(0.00)\end{array}$ & $\begin{array}{c}16.67 \\
(66.67)\end{array}$ & $\begin{array}{c}9.44 \\
(3)\end{array}$ & $0.024 *$ \\
\hline $\begin{array}{l}\text { Adhesive } \\
\text { failure } \\
\text { (dentine- } \\
\text { adhesive) }\end{array}$ & $\begin{array}{c}1.25 \\
(5.78)\end{array}$ & $\begin{array}{c}0.00 \\
(6.88)\end{array}$ & $\begin{array}{c}17.50 \\
(68.75)\end{array}$ & $\begin{array}{c}9.58 \\
(3)\end{array}$ & $0.022^{*}$ \\
\hline
\end{tabular}

Values are median (interquartile range) in percentages.

* Significant if $\mathrm{p}<0.05$

\section{SEM QUALITATIVE EVALUATION}

Figure 1 shows SEM image of selected OS specimen, with respect to the hybrid layer thickness. A well-defined hybrid layer, which was thick and continuous, can be seen. Numerous well defined resin tags were observed infiltrating into the dentine tubules, with the length ranged between 27 to $31 \mu \mathrm{m}$. Figure 2 shows SEM image of hybrid layer of selected OV specimen. It shows a welldefined and continuous hybrid layer, but thinner compared

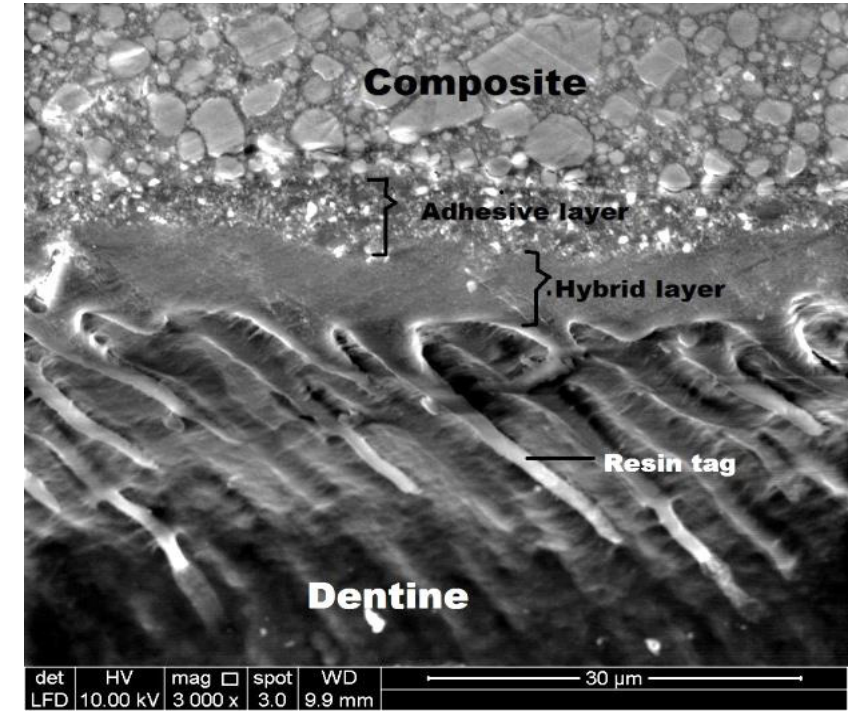

Figure 1: SEM image of OS specimen showing a thick hybrid layer.

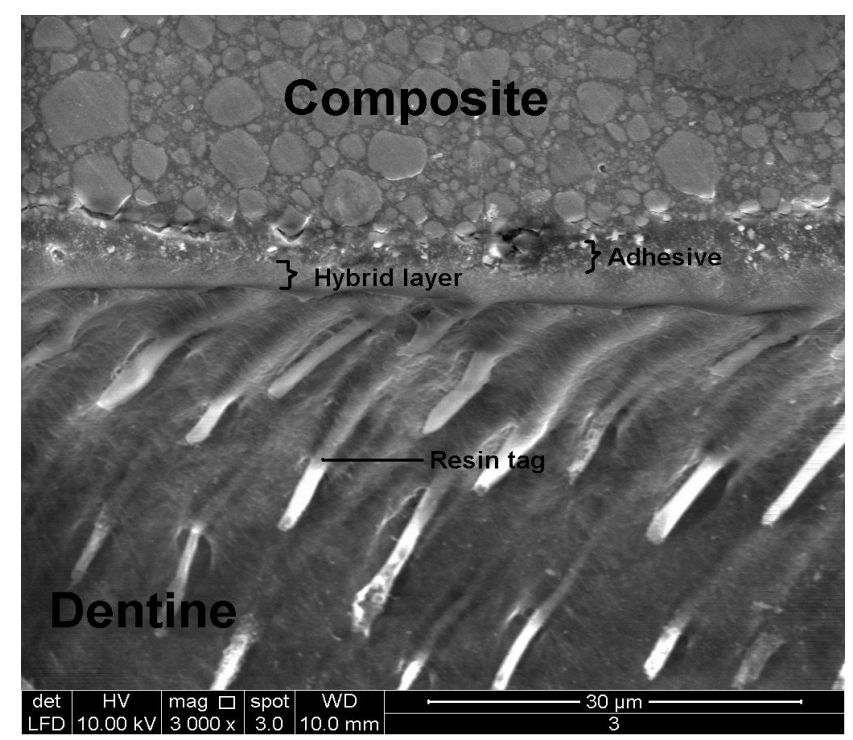

Figure 2: SEM image of OV specimen showing a thinner hybrid layer compared to OS.

to OS. There were numerous short resin tags seen with the length ranged between 9 to $19 \mu \mathrm{m}$.

SEM image in Figure 3 shows a very thin, continuous and poorly defined hybrid layer in selected SBU specimen. No resin tags were observed in this group. SEM image of selected SBU + etchant specimen in Figure 4 shows a moderately-defined hybrid layer and considerably thick. Less number of resin tags was noted with length ranged between 13 to $21 \mu \mathrm{m}$. Figure 5 and 6 showed examples of cohesive and adhesive failures observed in SBU + etchant and SBU groups respectively. 


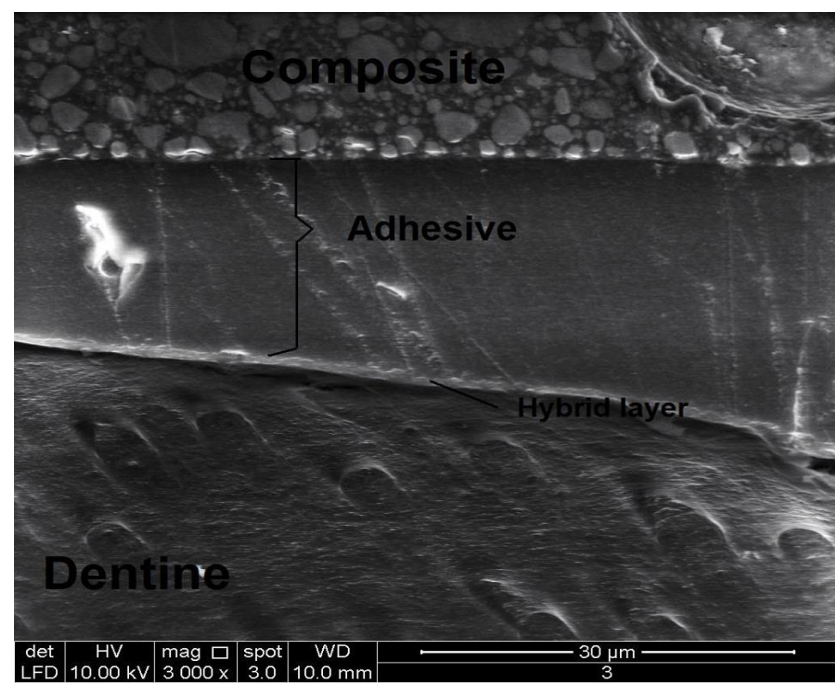

Figure 3: SEM image of SBU specimen showing a poorly defined hybrid layer with no resin tags detected.

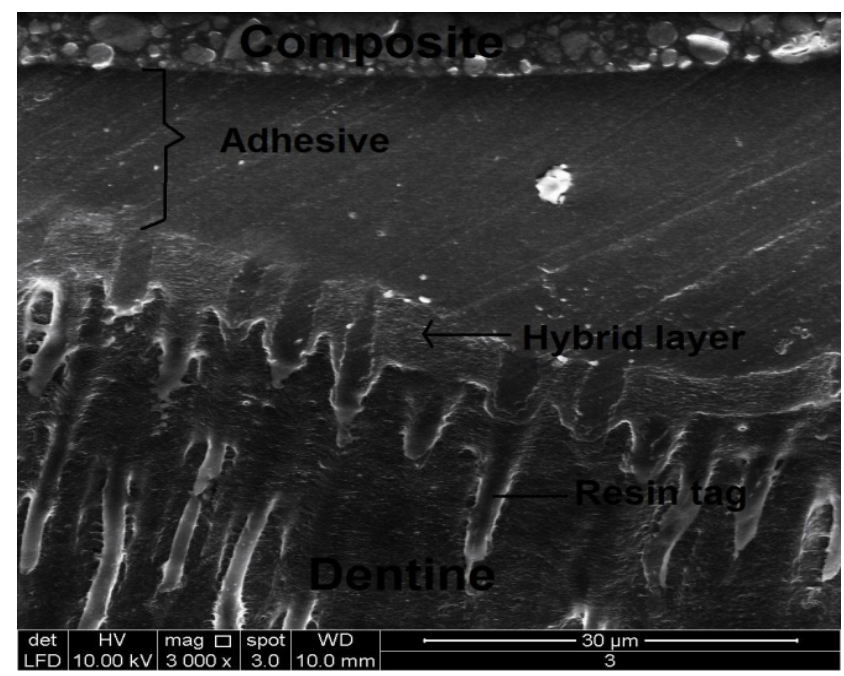

Figure 4: SEM image of specimen SBU + etchant showing an irregular and thick hybrid layer.

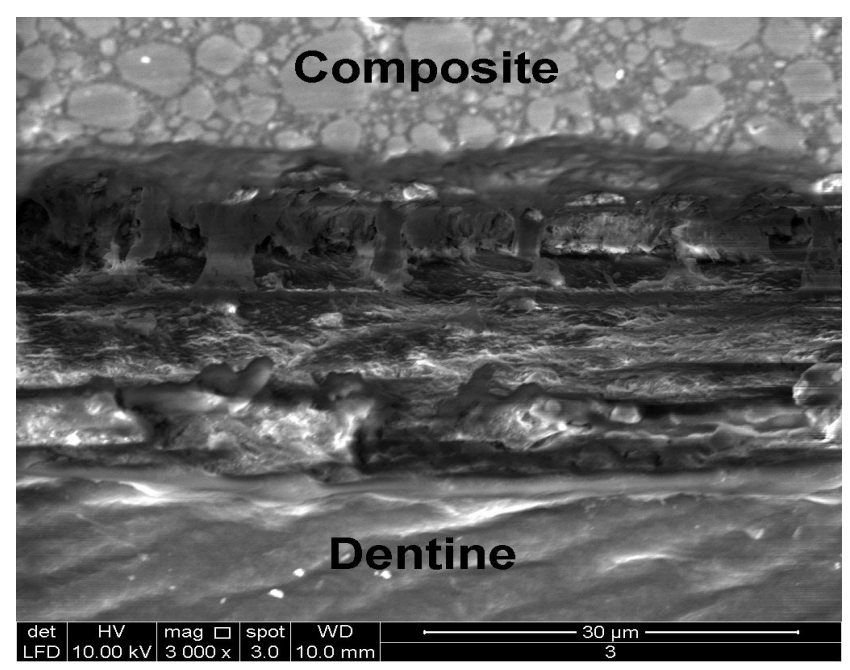

Figure 5: SEM image showing cohesive failure within adhesive layer itself in SBU+ etchant specimen.

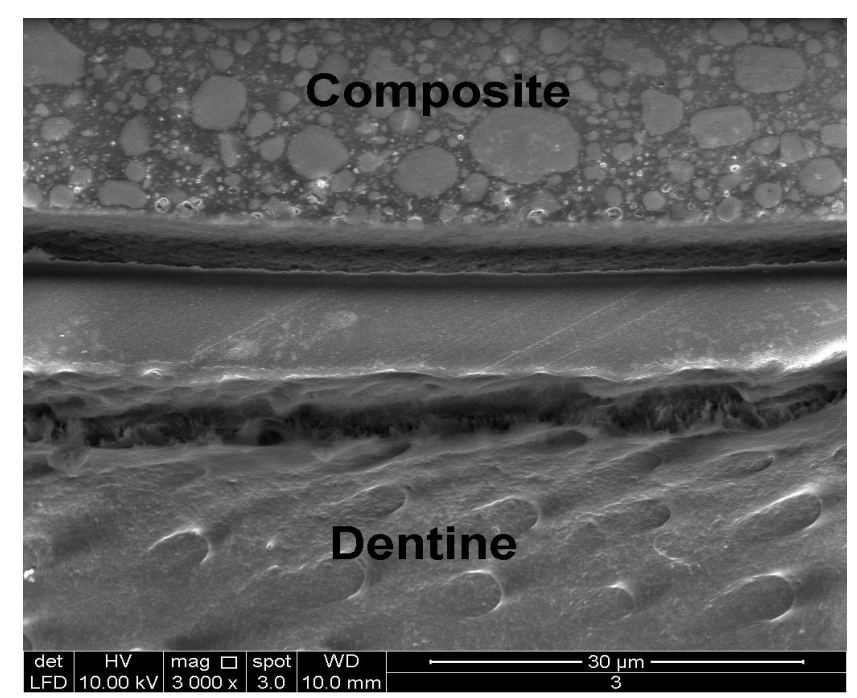

Figure 6: SEM image showing adhesive failure between composite-adhesive junction and dentine-adhesive junction in SBU specimen.

\section{DISCUSSION}

The purpose of this study was to evaluate and compare the bonding performance of the three latest adhesive systems (OS, OV and SBU). The evolution of these three latest adhesive systems could address the main concern of adhesive dentistry, which was to enhance the sealing and strength of restorations. Specifically with regard to the recent single bottle self-etch adhesive (SBU), it claimed an effective and consistent bonding in either modes of technique such as total-etch or self-etch. However, the present study showed that there were micro-morphological differences at the resin-dentine bonded interface when using either the total-etch or self-etch adhesive system. The null hypothesis was then rejected.

The most noticeable difference was the hybrid layer thickness. Total-etch adhesives (OS, Group 1) showed a significantly greater hybrid layer thickness compared to self-etching adhesive systems (OV and SBU)(Table 2 ), This observation was in agreement with previous similar studies $(24,25)$ and could be due to the complete dissolution of the smear layer and smear plug following greater depth of dentine demineralization promoted by the $37.5 \%$ phosphoric acid (25). Most of the adaptation failures (adhesion and cohesion) were detected in the specimens of SBU, self-etch mode (Table 3 ). In comparison with other groups of specimens, SBU (self-etch mode) only showed significance relationship with $\mathrm{OS}$ and $\mathrm{OV}$ in adhesive failure. Formation of resin tags was observed in the other groups of specimens but it was not visible in specimens of SBU, self-etch mode (Figure 3).

In order to minimize measurement bias between operators, cavity preparations were done by one operator while the restorative procedures were carried out by another operator. The cavities were restored with different adhesive 
systems according to the manufacturers' instructions to prevent procedural errors. All cavities were restored with two increments of composite to reduce polymerization shrinkage. To allow optimal observation of specimens under SEM, the sectioned samples were polished with increasing grit of silicon carbide paper. In addition, the specimens were demineralized and deproteinized by $\mathrm{HCl}$ and $\mathrm{NaOCl}$ to ensure optimal exposure of hybrid layer and resin tags. In this study, a minimum of three SEM images were taken for each specimen. In addition, at least three independent readings of hybrid layer thickness were taken from each SEM image. This was done to ensure the average value obtained for each samples were representative of the whole specimen.

Cohesive and adhesive failures were calculated by using point counting technique (26). Firstly, all SEM images were standardized to a fixed dimension. Three horizontal lines were drawn at the composite-adhesive junction, adhesive layer and dentine-adhesive junction respectively. Fourty vertical lines were drawn throughout the image intersecting the horizontal lines. The numbers of intersection point with failure were recorded according to adhesive and cohesive failure. The percentages of failure were counted by the ratio of total number of intersection points with failure to total number of intersection point.

Statistically, modification of sample size of group 3 (SBU) has been done as one out of ten samples showed an exceptionally thick hybrid layer that did not seem to fit with the majority of the data set. Subsequently, the initial sample size of fourty was reduced to thirty nine prior to statistical analysis. This outlier was eliminated to improve the accuracy of the overall statistical results.

It can be said that there was a discrepancy in bonding performance detected in the present study among pairs of groups between SBU (self-etch) and SBU + etchant (total-etch); OS and OV; OS and SBU (self-etch); OV and SBU (self-etch) as a significant difference was observed in the hybrid layer thickness. This is most probably due to the difference in acidity of etchant present in self-etch mode and total-etch mode. Total-etch utilizes phosphoric acid, a strong acid with an approximate $\mathrm{pH}$ of less than 0.5 to completely dissolve the smear layer and increase the depth of dentine demineralization with greater exposure of collagen fibre $(27,28)$. In contrast, the acidity stems from the SBU originate from the addition of acidic phosphorylated monomer in an aqueous solution to provide acidity, which is commonly less acidic ( $\mathrm{pH}$ 2.7) than total-etch systems. In addition, demineralizing action in the self-etch procedure will be affected by the residue dentine demineralization by-products which may act as buffering agent. A more superficial infiltration of the adhesive system is achieved when these by-products were synergized with incomplete removal of smear layer, thus resulting in decrease thickness of the hybrid layer compared to total-etch adhesive systems $(28,29,30)$.
There was significant difference in hybrid layer thickness detected between the two self-etching adhesives (OV and SBU). Higher concentration acid in $\mathrm{OV}(\mathrm{pH}$ 1.6) as compared to $\mathrm{SBU}(\mathrm{pH} 2.7)$ results in more profound removal of smear layer and greater depth of demineralization thus, thicker hybrid layer. Single-bottle self-etching adhesives (SBU) could be more hydrophilic than two-bottle self-etching adhesives (OV), which is necessary for acid monomer's ionization (8). This implies that they contain smaller amount of hydrophobic monomers thus this explains their high hydrophilicity and low viscosity, and responsible for the creation of a sparser layer of dentine bonding (31). A relatively low acid concentration may account for the absence of resin tags formation in SBU due to incomplete removal of smear layer (32).

Higher adaptation (adhesion and cohesion) failure rate of SBU could be explainable by previous studies on water concentration in single-bottle self-etch adhesive and its effect in bonding efficacy to dentine. As aforementioned, a high hydrophilicity of single-bottle selfetch adhesives is necessary for acid ionization. However, this may disrupt the bonding durability because they tend to attract water. Partial evaporation of water will give rise to formation of microscopic water tubules at the adhesive interfaces. Although evaporation is successful, water will flow back from the bonded dentine through the hybrid and adhesive layers into composite-adhesive interface. This phenomenon might cause partial polymerization of the adhesives, lead to an inferior mechanical properties, and subsequently higher susceptibility of degradation $(31,33,34)$.

Nevertheless, it is possible that these adaptation gaps may have originated from or may have been increased due to desiccation caused from SEM procedure. However, since no gaps were observed in the other adhesive system groups, and since all specimens were treated equally, the differences are attributed to the bonding potentiality of the SBU system.

\section{CONCLUSION}

Within the limitation of this study, all the adhesive systems were able to form hybrid layer. Resin tags were detected in all the adhesive systems except in SBU (self-etch). Total-etch adhesive (OS) presented the thickest hybrid layer among the adhesive systems. SBU with total-etch mode clearly presented a thicker hybrid layer compared to self-etch mode. There was no correlation between hybrid layer thickness and adaptation failure. Further laboratory testing on these adhesive systems should be conducted to find the relationship between thickness of hybrid layer and presence of resin tags with bond strength. 


\section{ACKNOWLEDGEMENT}

The authors would like to thank the University of Malaya for financing this project under grant no: RG531-13HTM. We would like to thank Associate Prof. Dr. Noor Lide Abu Kasim for her assistance in statistical analysis.

\section{DECLARATION OF INTEREST}

The authors report no conflicts of interest. The authors alone are responsible with the content of this article.

\section{REFERENCES}

1. Buonocore M. A simple method of increasing the adhesion of acrylic filling materials to enamel surfaces. J Dent Res. 1955;34(6):849-53.

2. Buonocore M, Matsui A, Gwinnett A. Penetration of resin dental materials into enamel surfaces with reference to bonding. Arch Oral Biol. 1968;13(1): 61-IN20.

3. Buonocore M. Principles of adhesive retention and adhesive restorative materials. J Am Dent Assoc. 1963;67:382.

4. Kukletová M, Halačková Z, Horký D, Matoušek A, Gojišová E, Cihlář J. Comparison of dentine-resin interface in total-etch and self-etching adhesives using electron microscopy. Prague Medical Report. 2007;108(4), 358-67.

5. Nakabayashi N, Saimi Y. Bonding to intact dentine. J Dent Res. 1996;75(9): 1706-15.

6. Nakabayashi N, Kojima K, Masuhara E. The promotion of adhesion by the infiltration of monomers into tooth substrates. J Biomed Mater Res.1982;16:265-73.

7. Toledano M, Osorio R, Albaladejo A, Aguilera FS, Osorio E. (2006). Differential effect of in vitro degradation on resin-dentin bonds produced by selfetch versus total-etch adhesives. J Biomed Mater Res Part A. 2006;77(1):128-35.

8. Van Meerbeek B, De Munck J, Yoshida Y, Inoue S, Vargas M, Vijay P, Vanherle G. Adhesion to enamel and dentine: current status and future challenges. Oper Dent. 2003;28(3):215-35.

9. Inoue S, Vargas M A, Abe Y, Yoshida, Y, Lambrechts P, Vanherle G, Van Meerbeek B. Microtensile bond strength of eleven contemporary adhesives to enamel. Am J Dent. 2003;16(5), 329-34.

10. Pashley D H, Tay F R, Breschi L, Tjäderhane L, Carvalho R M, Carrilho M, Tezvergil-Mutluay A. State of the art etch-and-rinse adhesives. Dent Mater. 2011;27(1), 1-16.
11. Weston JF. Contemporary adhesive systems and resin composites. 2013.

12. http://www.dentallearning.net/files/Weston Composites_Adhesive_Web.pdf

13. Breschi L, Perdigao J, Gobbi P, Mazzotti G, Falconi M, Lopes M. Immunocytochemical identification of type I collagen in acid-etched dentin. J Biomed Mater Res Part A. 2003;66(4):764-9.

14. Erickson RL, Barkmeier WW, Latta MA. The role of etching in bonding to enamel: a comparison of selfetching and etch-and-rinse adhesive systems. Dent Mater. 2009;25(11):1459-67.

15. Frankenberger R, Lohbauer U, Roggendorf M J, Naumann M, Taschner M. Selective enamel etching reconsidered: better than etch-and-rinse and selfetch? J Adhes Dent. 2008;10(5): 339.

16. Perdigão J, Sezinando A, Monteiro PC. Laboratory bonding ability of a multi-purpose dentine adhesive. Am J Dent. 2012;25(3):153.

17. Tay FR, Pashley DH.Aggressiveness of contemporary self-etching systems: I: Depth of penetration beyond dentine smear layers. Dent Mater. 2001;17(4): 296308.

18. Pashley, D, Carvalho R. Dentine permeability and dentine adhesion. J Dent.1997;25(5):355-72.

19. Kaaden C, Powers J M, Friedl K H, Schmalz G. Bond strength of self-etching adhesives to dental hard tissues. Clin Oral Invest. 2002;6(3):155-60.

20. Walshaw PR, Tam LE, McComb D. Bond failure at dentin-composite interfaces with 'single-bottle' adhesives. J Dent. 2003;31(2):117-25.

21. Von Fraunhofer J A (2012). Adhesion and cohesion. Inter J Dent. 2012.

22. Van Meerbeek B, Vargas M, Inoue S, Yoshida Y, Perdigao J, Lambrechts P, Vanherle G. Microscopy investigations. Techniques, results, limitations. Am J Dent. 2000;13(Spec No):3D.

23. Hegde M N, Hegde P, Chandra C R. Morphological evaluation of new total etching and self etching adhesive system interfaces with dentin. J Conserv Dent. 2012;15(2):151.

24. Schein M T, Bocangel J S, Nogueira G E C, Schein $P$ A L. SEM evaluation of the interaction pattern between dentin and resin after cavity preparation using Er: YAG laser. J Dent. 2003;31(2):127-35.

25. Albaladejo A, Osorio R, Toledano M, Ferrari M. Hybrid layers of etch-and-rinse versus self-etching adhesive systems. Med Oral Patol Oral Cir Bucal. 2010;15(1):112-8.

26. Machado L S, Sundfeld R H, Cardoso J D, Oliveira F G, da Silva A P, Delicio, G, Sundefeld M L. Observation of tags and hybrid layer of a single bottle conventional adhesive system and a self- 
etching adhesive system, on sound dentin. Acta Odont Latinoam. 2009; 22(3):183.

27. Yahya NA, Todd RI. Influence of $\mathrm{C}$ doping on the fracture mode and abrasive wear of $\mathrm{Al}_{2} \mathrm{O}_{3}$. J Euro Ceram Soc. 2012;32(16):4003-7.

28. Miyazaki M, Tsubota K, Onose H, Hinoura K. Influence of adhesive application duration on dentin bond strength of single-application bonding systems. Oper Dent. 2001;27(3): 278-83.

29. Tay F R, Pashley D H, Suh B, Carvalho R M, Itthagarun A. Single-step adhesives are permeable membranes. J Dent. 2002;30(7):371-82.

30. Pashley DH, Tay FR.Aggressiveness of contemporary self-etching adhesives: Part II: etching effects on unground enamel. Dent Mater. 2001; 17(5):430-44.

31. Pashley E L, Agee K A, Pashley D H, Tay F R. Effects of one versus two applications of an unfilled, all-inone adhesive on dentine bonding. J Dent. 2002; 30(2): 83-90.
32. Tay FR, Pashley DH. Have dentine adhesives become too hydrophilic? J Canad Dent Assoc. 2003;69(11):726-32.

33. Kenshima S, Francci C, Reis A, Loguercio A D. Conditioning effect on dentin, resin tags and hybrid layer of different acidity self-etch adhesives applied to thick and thin smear layer. J Dent. 2006;34(10):77583.

34. Hiraishi $N$, Nishiyama $N$, Ikemura $K$, Yau J Y Y, King N M, Tagami J, Tay F R. Water concentration in self-etching primers affects their aggressiveness and bonding efficacy to dentin. J Dent Res.2005;84(7):653-8.

35. Tay F R, Frankenberger R, Krejci I, Bouillaguet S, Pashley D H, Carvalho R M, Lai C N S. Singlebottle adhesives behave as permeable membranes after polymerization. I. In vivo evidence. J Dent. 2004;32(8): 611-21. 